\title{
ПРОТИВОВИРУСНАЯ АКТИВНОСТЬ СУММЫ АЛКАЛОИДОВ GENISTA TINCTORIA И ЕЕ ОТДЕЛЬНЫХ ФРАКЦИЙ В ОТНОШЕНИИ ВИРУСА ГРИППА A(H1N1)PDM09
}

(C) И.П. Цыпышева ${ }^{1}$, Е.Г. Галкин ${ }^{1}$, А.В. Ковальская ${ }^{1}$, П.Р. Петрова ${ }^{2}$, И.П. Байкова Я.Р. Орианская ${ }^{3}$, В.А. Федорова ${ }^{3}$, Н.И. Федоров ${ }^{4}$, Ф.З. Галин ${ }^{1,2}$, В.В. Зарубаев ${ }^{3}$

${ }^{1}$ Уфимский институт химии Российской академии наук, пр. Октября, 71, Уфра, Республика Башкортостан, 450054 (Россия), e-mail: tsipisheva@anrb.ru

${ }^{2}$ Башкирский государственный университет, ул. Заки Валиди, 32, Уфра, Республика Башкортостан, 450076 (Россия),

${ }^{3}$ НИИ гриппа Минздрава РФ, ул. Профрессора Попова, 15/17, СанктПетербург, 197376 (Россия)

${ }^{4}$ Уфимский институт биологии Российской академии наук, пр. Октября, 69, Уфа, Республика Башкортостан, 450054 (Россия)

Изучена способность алкалоидов надземной части Genista tinctoria L. (дрок красильный), собранного в период цветения в Альшеевском районе Республики Башкортостан, ингибировать репродукцию вируса гриппа A(H1N1)pdm09. Компонентный состав суммы алкалоидов и отдельных фракций определен хромато-массспектрометрическим методом. Цитотоксичность и противогриппозные свойства алкалоидов G. tinctoria изучены in vitro в культуре клеток MDCK в отношении штамма вируса гриппа A/California/07/09 (H1N1)pdm09, в качестве препарата сравнения использован римантадин. На основании полученных данных рассчитаны $50 \%$ цитотоксическая доза $\mathrm{CC}_{50}, 50 \%$ ингибирующая доза $\mathrm{IC}_{50}$, а также индекс селективности $\mathrm{SI}$, характеризующий избирательность действия образца в отношении вируса. Согласно полученным данным, наибольшей противогриппозной активностью обладает фракция 4 суммы алкалоидов G. tinctoria $(\mathrm{SI}=10)$, в которой содержатся алкалоиды $12-N$-метилцитизин, $(-)$-цитизин, $\mathrm{d}$-лупанин, 12-N-формилцитизин, анагирин, баптифолин, а также фракция $5(\mathrm{SI}=7)$, содержащая $(-)$-цитизин, анагирин и баптифолин. Анагирин является мажорным компонентом фракции 4 , его содержание составляет $0,13 \%$ от веса воздушно-сухого сырья, а баптифолин - 5, его содержание $0,14 \%$. Необходимо отметить, что по сравнению с суммой алкалоидов G. tinctoria и фракциями 2 и $\mathbf{3}$, фракции 4 и 5, обогащенные тетрациклическими хинолизидиновыми алкалоидами (анагирином и баптифолином), проявляют более выраженную противогриппозную активность. Выявленная закономерность может служить основанием для дальнейшей оптимизации противогриппозных свойств указанных алкалоидов посредством их химических трансформаций. тивности.

Ключевые слова: Genista tinctoria L., хинолизидиновые алкалоиды, вирус гриппа A(H1N1)pdm09, индекс селек-

Сокращения: AMDIS - automated mass spectral deconvolution and identification system (система автоматической деконволюции и идентификации масс-спектров); CC - цитотоксическая концентрация; HBV - вирус гепатита B; HCV вирус гепатита C; HIV - вирус иммунодефицита человека; HSV - вирус простого герпеса; IC - ингибирующая концентрация; MDCK - Madin-Darby anine kidney cell (клетки почек собаки); MEM - minimum essential medium (среда Игла); MTT - 3-[4,5-диметил-2-тиазолил]-2,5-дифенилтетразолий бромид; SI - индекс селективности; RRT - относительное время удерживания; ВСС - воздушно-сухое сырье; РКЭ - развивающиеся куриные эмбрионы.

Работа выполнена с использованием оборудования ЦКП «Химия» УфИХ РАН.

\section{Введение}

Цыпьшева Инна Петровна - старший научный сотрудник лаборатории биоорганической химии и катализа, кандидат химических наук, e-mail: tsipisheva@anrb.ru

Продолжение на С. 72.
Лекарственные растения традиционно применяются для лечения инфекционных заболеваний, включая вирусные [1-7]. Известно, что экс-

\footnotetext{
* Автор, с которым следует вести переписку.
} 
тракты растений родов Sophora, Acacia, Chamaecytisus, Thermopsis семейства бобовых (Fabaceae) - основных продуцентов хинолизидиновых алкалоидов - активны в отношении вирусов гепатита C (HCV) и B (HBV), вируса простого герпеса I (HSV-I), вируса гриппа A (H1N1) и некоторых других [8-15]. Кроме того, выделенный в индивидуальном виде алкалоид алоперин проявляет исключительно высокие противогриппозные свойства [16], а его синтетические производные рассматриваются в качестве перспективных агентов для терапии синдрома приобретенного иммунодефицита, вызываемого вирусом HIV-1 [17].

Недавно нами показано, что отдельные фракции сумм алкалоидов Thermopsis schischkinii Czefr. и Chamaecytisus ruthenicus (Fisch. Ex Woloszcz.) Klaskova, произрастающих на территории Республики Башкортостан и Южного Урала, проявляют заметную противогриппозную активность [14, 15]. С целью выявления алкалоидоносных видов среди растений этого семейства, обладающих противогриппозной активностью, а также структурных типов хинолизидиновых алкалоидов, отвечающих за ее проявление, нами исследованы цитотоксичность суммы алкалоидов Genista tinctoria L. и ее отдельных фракций, а также их способность ингибировать in vitro репродукцию вируса гриппа A(H1N1)pdm09. Данный тип биологической активности для G. tinctoria до настоящего времени не изучался.

\section{Экспериментальная часть}

Сбор и подготовка растительного сырья. В качестве исходного материала для исследования использована надземная часть G. tinctoria, собранная в фенофазу цветения (16.06.2014) в лесостепной зоне Республики Башкортостан (Альшеевский район). Видовая принадлежность растения определена д.б.н. Н.И. Федоровым (Уфимский институт Биологии РАН). Гербарный образец G. tinctoria хранится в гербарии ИБ УНЦ РАН (№ 203-2014). Растения срезали на высоте 7-10 см от основания, сразу нарезали на части (35 см) и сушили при температуре $20-25^{\circ} \mathrm{C}$.

Выделение суммы алкалоидов и хроматографическое разделение. Экстракцию 100 г измельченного воздушно-сухого сырья проводили водно-ацетоновой смесью (1:9) методом настаивания до получения отрицательной пробы с кремневольфрамовой кислотой. Сумму алкалоидов извлекали классическим методом в виде свободных оснований согласно [18], сначала переводя алкалоиды в соли (обработка 5\% водным раствором серной кислоты), затем удаляя из кислого экстракта примеси «неалкалоидного» характера (экстракция диэтиловым эфиром и хлороформом последовательно), далее обрабатывая кислый слой бикарбонатом натрия (до $\mathrm{pH}=11$ ) и экстрагируя свободные основания хлороформом. Полученные хлороформные экстракты объединяли, сушили безводным $\mathrm{Na}_{2} \mathrm{SO}_{4}$ и концентрировали. Вес суммы алкалоидов надземной части G. tinctoria составил 0,9 г (0,9\% от веса воздушно-сухого сырья).

Разделение суммы алкалоидов проводили методом колоночной хроматографии на силикагеле 60

Галкин Евгений Григорьевич - старший научный сотрудник, кандидат химических наук, e-mail: spectr@anrb.ru

Ковальская Алена Витальевна - научный сотрудник, кандидат химических наук,

e-mail: alenaminilbaeva@rambler.ru

Петрова Полина Радиковна - аспирант кафедры биоорганической химии, e-mail: rradimir@mail.ru Байкова Ирина Петровна - старший научный сотрудник, кандидат химических наук, e-mail: spectr@anrb.ru Оршанская Яна Рафаэльевна - младший научный сотрудник лаборатории безопасности лекарственных средств, e-mail: yana.orshanskaya@influenza.spb.ru Федорова Виктория Александровна - младший научный сотрудник лаборатории безопасности лекарственных средств, e-mail: viktoria.fedorova@influenza.spb.ru

Федоров Николай Иванович - заведующий лабораторией экологии растительных ресурсов, доктор биологических наук, e-mail: fedorov@anrb.ru

Галин Фанур Зуфарович - главный научный сотрудник, профессор, доктор химических наук, e-mail: galin@anrb.ru Зарубаев Владимир Викторович - старший научный сотрудник лаборатории безопасности лекарственных средств, кандидат биологических наук, e-mail: zarubaev@influenza.spb.ru с размером частиц 0,05-0,1 мм (MACHEREYNAGEL, Германия). Полярность элюента повышали в следующем порядке: $\mathrm{CHCl}_{3}$, $\mathrm{CHCl}_{3}: \mathrm{MeOH}=97: 3, \mathrm{CHCl}_{3}: \mathrm{MeOH}=9: 1$, $\mathrm{CHCl}_{3}: \mathrm{MeOH}=7: 1, \mathrm{MeO}$. Получили пять фракций 1-5, вес которых составил 0,09, 0,07, 0,23, 0,29 и 0,227 г соответственно.

Хромато-масс-спектрометрические исследования. Хромато-масс-спектрограммы регистрировались на приборе Thermo Finnigan MAT95XР, метод ионизации электронный удар $70 \mathrm{eV}$, температура инжектора $250{ }^{\circ} \mathrm{C}$, колонка HP-5MS, 30 м × 0,25 мм $\times 0,25$ мкм толщина фазы; режим: начальная температура $120^{\circ} \mathrm{C} 3$ мин, изотерма $250{ }^{\circ} \mathrm{C} 10$ мин. Компоненты исследуемых смесей идентифицировали по полным масс-спектрам и по библиотеке хромато-масс-спектрометрических данных при использовании систем обработки данных AMDIS (automated Mass Spectral 
Deconvolution and Identification System [19]) и дополнительно подтверждали методом «свидетелей», в качестве которых использовали алкалоиды (-)-цитизин, 12-N-метилцитизин, d-лупанин, анагирин и баптифолин, выделенные нами ранее [20-22]. Количественный анализ выполняли методом внутренней нормировки по площадям хроматографических пиков без использования корректирующих коэффициентов. За 100\% принимали сумму площадей пиков компонентов. Содержание алкалоидов в экстрактах рассчитывали в \% от веса воздушно сухого сырья (ВСС) - 100 г измельченного растения.

Цитотоксичность и противогриппозная активность. Цитотоксические свойства и противогриппозная активность суммы алкалоидов G. tinctoria и фракций, содержащих алкалоиды, были исследованы в ФГБУ «НИИ гриппа» МЗ РФ (С.-Петербург). В эксперименте использовали штамм вируса гриппа A/California/07/09(H1N1)pdm09, полученный из Центра по контролю за заболеваемостью (CDC, Atlanta, USA). В качестве препарата сравнения использовали препарат римантадин, методики изучения цитотоксических свойств и противогриппозной активности подробно описаны в $[23,24]$.

Клетки почек собаки MDCK (Madin-Darby canine kidney cell) сеяли на 96-луночные микропланшеты (Orange scientific № 5530100) по 0,2 мл в лунку и культивировали при $37^{\circ} \mathrm{C}$ при 5\% $\mathrm{CO}_{2}$ до образования монослоя.

Для определения цитотоксичности соединений готовили серию двукратных разведений каждого из препаратов от 1000 до 4 мкг/мл на среде МЕМ (Биолот, Санкт-Петербург). Клетки инкубировали в присутствии растворенных препаратов в течение 48 часов при $36{ }^{\circ} \mathrm{C}$ и $5 \% \mathrm{CO}_{2}$, после чего степень деструкции клеточного монослоя оценивали при помощи МТТ-теста. С этой целью отмытые от среды клетки инкубировали 1 ч с раствором MTT (Calbiochem №475989, 0,5 мкг/мл) в физиологическом растворе. Лунки промывали и заливали 0,1 мл DMSO, после чего оптическую плотность клеток измеряли на микропланшетном ридере Victor ${ }^{2} 1420$ (Perkin Elmer, Финляндия) при длине волны 535 нм. На основании полученных данных рассчитывали концентрацию препарата в лунке, при которой происходит 50\% деструкция клеточного монослоя $\left(\mathrm{CC}_{50}\right)$.

Вирус гриппа культивировали в 10-11-дневных развивающихся куриных эмбрионах (РКЭ), вводя в аллантоисную полость 1-10 ИД50/0,2 мл вируссодержащей жидкости. Вирусы гриппа культивировали 48 ч при $+36^{\circ} \mathrm{C}$.

В культуру клеток MDCK добавляли препараты, растворенные в среде MEM (среда Игла) и выдерживали планшеты 1 ч при $36^{\circ} \mathrm{C}$ и $5 \% \mathrm{CO}_{2}$. Клеточную культуру заражали 10 -кратными разведениями вируса от $10^{-1}$ до $10^{-6}$. Планшеты с вирусом и препаратами инкубировали в $\mathrm{CO}_{2}$ инкубаторе 48 ч при $36{ }^{\circ} \mathrm{C}$ и $5 \% \mathrm{CO}_{2}$. По истечении срока инкубации культуральную жидкость переносили в соответствующие лунки планшетов с круглым дном и вносили равное количество 1\% суспензии куриных эритроцитов. Реакцию гемагглютинации учитывали через 40 мин при комнатной температуре. За титр вируса принимали величину, противоположную десятичному логарифму максимального разведения вируса, способного вызвать полную агглютинацию эритроцитов. На основании полученных результатов рассчитывали 50\% ингибирующую концентрацию $\left(\mathrm{IC}_{50}\right)$ для каждого препарата, снижающую репродукцию вируса вдвое, и индекс селективности (отношение $\mathrm{CC}_{50}$ к $\mathrm{IC}_{50}$ ).

\section{Обсуждение результатов}

Согласно данным хромато-масс-спектрометрическеского анализа, основными компонентами суммы алкалоидов G. tinctoria, собранного в период цветения, являются алкалоиды $12-N$-метилцитизин, (-)цитизин, d-лупанин, $N$-формилцитизин, анагирин и баптифолин (табл. 1), что согласуется с нашими предыдущими данными [22].

На основании результатов проведенных in vitro исследований цитотоксической активности суммы алкалоидов G. tinctoria и фракций 2-5 (табл. 2) установлено, что сумма алкалоидов G. tinctoria, а также фракций 3-5, не проявляют заметной цитотоксичности. Значения их $\mathrm{CC}_{50}$ составляют более 300 мкг/мл, в то же время фракция 2 в концентрации 88 мкг/мл приводит к деструкции 50\% клеточного монослоя клеток линии MDCK.

Значения $\mathrm{IC}_{50}$, характеризующие способность тестируемых фракций ингибировать репродукцию вируса гриппа A(H1N1)pdm09, лежат в более узком интервале концентраций - от 15 до 89 мкг/мл, и значения их достаточно высоки по сравнению с $[16,17]$. Необходимо отметить, что наиболее цитотоксичная фракция 2 является и наиболее активной, ее $\mathrm{IC}_{50}$ составляет 15 мкг/мл. 
Таблица 1. Алкалоидный состав суммы алкалоидов G. tinctoria и фракций 2-5

\begin{tabular}{|c|c|c|c|c|c|c|c|c|}
\hline \multicolumn{4}{|c|}{ Фракция } & $\Sigma$ & 2 & 3 & 4 & 5 \\
\hline \multicolumn{4}{|c|}{ Вес фракции, г } & 0,9 & 0,07 & 0,23 & 0,29 & 0,22 \\
\hline \multicolumn{4}{|c|}{ Элюент, $\mathrm{CHCl}_{3}: \mathrm{MeOH}$} & - & $97: 3$ & $9: 1$ & $7: 1$ & $\mathrm{MeOH}$ \\
\hline Алкалоид & $\mathrm{RRT}^{\mathrm{a}}$ & $\mathrm{M}^{+}$ & $Q^{6}$ & \multicolumn{5}{|c|}{ Алкалоидный состав, \% ${ }^{\text {в }}$} \\
\hline 12-N-метилцитизин & 0,94 & 204 & 97 & 0,05 & + & 0,04 & 0,01 & - \\
\hline (-)-Цитизин & 1,00 & 190 & 98 & 0,04 & - & 0,01 & 0,02 & 0,01 \\
\hline d-Лупанин & 1,22 & 248 & 96 & 0,06 & + & 0,04 & 0,02 & - \\
\hline 12-N-формилцитизин & 1,51 & 218 & 94 & 0,11 & 0,01 & 0,07 & 0,03 & - \\
\hline Анагирин & 1,54 & 244 & 98 & 0,32 & 0,05 & 0,07 & 0,13 & 0,07 \\
\hline Баптифолин & 1,91 & 260 & 89 & 0,23 & - & + & 0,08 & 0,14 \\
\hline
\end{tabular}

Примечание. ${ }^{\text {a) }}$ Относительное время удерживания; $\left.{ }^{6}\right)$ Вероятность сходства зарегистрированных и библиотечных спектров; в) От веса ВСС.

Таблица 2. Противогриппозная активность суммы алкалоидов G. tinctoria и фракций 2-5

\begin{tabular}{c|c|c|c}
\hline Фракция & $\mathrm{CC}_{50}{ }^{\mathrm{a}}$, мкг/мл & $\mathrm{IC}_{50}{ }^{6}$, мкг/мл & $\mathrm{SI}$ \\
\hline$\Sigma$ & $>300$ & 81 & 4 \\
2 & 88 & 15 & 6 \\
3 & $>300$ & 89 & 3 \\
4 & $>300$ & 30 & 10 \\
5 & $>300$ & 41 & 7 \\
\hline
\end{tabular}

Примечание. ${ }^{\text {a) }}$ МТT-тест, клетки MDCK (ATCC \# CCL-34);

б) В отношении вируса гриппа A/California/07/09(H1N1)pdm09.
Оценка величин индекса селективности, характеризующего избирательность действия фракции по отношению к вирусу по сравнению с клетками, показала, что фракция 4 с $\mathrm{IC}_{50}$ $=30$ мкг/мл и $\mathrm{CC}_{50}>300$ мкг/мл, имеет наиболее высокий противогриппозный потенциал. Индекс ее селективности равен 10, что превосходит таковой для препарата сравнения римантадин $(\mathrm{SI}=5)[23]$.

\section{Заключение}

Таким образом, анализируя данные о взаимосвязи «структурный тип алкалоида - противогриппозная активность», можно сделать следующий вывод: фракции 4 и 5, обогащенные тетрациклическими хинолизидиновыми алкалоидами (анагирином и баптифолином), являются наиболее перспективными с точки зрения поиска новых противогриппозных агентов на основе веществ растительного происхождения, что согласуется с результатами, полученными нами ранее [14]. Данная закономерность является основанием для дальнейшей оптимизации противогриппозных свойств указанных алкалоидов посредством их химических трансформаций.

\section{Список литературы}

1. Lahlou M. The Success of Natural Products in Drug Discovery// Pharmacol. Pharm. 2013. Vol. 4. Pp. 17-31.

2. Hanessian S. Natural Products in Medicinal Chemistry. John Wiley\&Sons. 2013. 480 p.

3. Martin K.W., Ernst E. Antiviral agents from plants and herbs: a systematic review // Antivir. Ther. 2003. Vol. 8. Pp. 77-90.

4. Lin L.-T., Hsu W.-C., Lin C.-C. Antiviral Natural Products and Herbal Medicines // J. Tradit. Complement. Med. 2014. Vol. 4. Pp. 24-35.

5. Chattopadhyay D., Chawla-Sarkar M., Chatterjee T., Dey R.S., Bag P., Chakraborti S., Hassan Khan M.T. Recent advancements for the evaluation of anti-viral activities of natural products // New Biothecnol. 2009. Vol. 25. Pp. 347-368.

6. Kurokawa M., Shimizu T., Watanabe W., Shiraki K. Development of New Antiviral Agents from Natural Products // TOANTIMJ. 2010. Vol. 2. Pp. 49-57.

7. Sun F., Huang R. The medicinal potential of natural products for the development of anti-influenza agents // Curr. Drug Targets. 2014. Vol. 15. Pp. 175-183.

8. Tosun F., Kukukbayachy N., Adiguzel N., Ozkan S. Alkaloid profiles and biological activities of different Sophora jaubertii extracts // Turk. J. Pharm. Sci. 2010. Vol. 7. Pp. 1-8.

9. Raheel R., Ashraf M., Ejaz S., Javeed A., Altaf I. Assessment of the cytotoxic and anti-viral potential of aqueous extracts from different parts of Acacia nilotica (Linn) Delile against Peste des petits ruminants virus // Environ. Toxicol. Pharmacol. 2013. Vol. 35. Pp. 72-81.

10. Ding P.-L., Huang H., Zhou P., Chen D.-F. Quinolizidine Alkaloids with Anti-HBV Activity from Sophora tonkinensis // Planta Med. 2006. Vol. 72. Pp. 854-856.

11. Ding P.-L., Liao Z.-X., Huang H., Zhou P., Chen D.-F. (+)-12 $\alpha$-Hydroxysophocarpine, a new quinolizidine alkaloid and related anti-HBV alkaloids from Sophora flavescens // Bioorg. Med. Chem. Lett. 2006. Vol. 16. Pp. 1231-1235.

12. Atta-Ur-Rahman, Choudhary M.I., Parvez K., Ahmed A., Akhtar F., Nur-E-Alam M., Hassan N.M. Quinolizidine alkaloids from Sophora alopecuroides // J. Nat. Prod. 2000. Vol. 63. Pp. 190-192. 
13. Woo E.R., Kim H.J., Kwak J.H., Lim Y.K., Park S.K., Kim H.S., Lee C.K., Park H. Anti-herpetic activity of various medicinal plant extracts // Arch. Pharm. Res. 1997. Vol. 20. Pp. 58-67.

14. Tsypysheva I.P., Galkin E.G., Baikova I.P., Fedorov N.I., Petrova P.R., Orshanskaya Ya.R., Fedorova V.A., Zarubaev V.V. Activity of Thermopsis schischkinii alkaloids against influenza A(H1N1)pdm09 virus // Chem. Nat. Compd. 2015. Vol. 51. Pp. 1003-1005.

15. Цыпышева И.П., Галкин Е.Г., Федоров Н.И., Оршанская Я.Р., Федорова В.А., Зарубаев В.В. Активность Chamaecytisus ruthennicus (Fabaceae) в отношении вируса гриппа А (H1N1) // Химия растительного сырья. 2016. № 2. C. 153-156.

16. Dang Z., Jung K., Zhu L., Lai W., Xie H., Lee K.-H., Huang L., Chen C.-H. Identification and Synthesis of Quinolizidines with Anti-Influenza A Virus Activity // ACS Med. Chem. Lett. 2014. Vol. 5. Pp. 942-946.

17. Dang Z., Zhu L., Lai W., Bogerd H., Lee K.-H., Huang L., Chen C.-H. Aloperine and Its Derivatives as a New Class of HIV-1 Entry Inhibitors // ACS Med. Chem. Lett. 2016. Vol. 7. Pp. 240-244.

18. Минина С.А., Каухова И.Е. Химия и технология фитопрепаратов. М., 2009. 560 с.

19. D’Arcy P., Mallard W.G., Reed J. Amdis Manual. Gaithersburg: National Institute of Standards and Technology. 2005.

20. Цыпышева И.П., Галкин Е.Г., Ерастов А.С., Каримова О.А., Байкова И.П., Рахимов Р.Г., Ковальская А.В., Халилова И.У., Абрамова Л.М., Юнусов М.С. Растительные источники хинолизидиновых алкалоидов на территории республики Башкортостан. I. Алкалоиды Thermopsis schischkinii и Thermopsis lanceolata ssp. sibirica (Fabaceae) в условиях интродукции // Химия растительного сырья. 2012. №4. С. 181-186.

21. Цыпышева И.П., Галкин Е.Г., Ерастов А.С., Каримова О.А., Байкова И.П., Ковальская А.В., Халилова И.У., Абрамова Л.М., Юнусов М.С. Растительные источники хинолизидиновых алкалоидов на территории Республики Башкортостан. II. Алкалоиды Thermopsis schischkini // Химия растительного сырья. 2013. №4. С. 55-60.

22. Tsypysheva I.P., Petrova P.R., Baykova I.P., Galkin E.G., Fedorov N.I., Galin F.Z., Yunusov M.S. Seasonal dynamics of alkaloids of Genista tinctoria L. growing at the Southern Ural region // Nat. Prod. Ind. J. 2015. Vol. 10. Pp. 215-218.

23. Tsypysheva I.P., Koval'skaya A.V., Lobov A.N., Zarubaev V.V., Karpinskaya L.A., Petrenko I.A., Nikolaeva E.A., Shtro A.A., Yunusov M.S. Search for compounds with antiviral activity among synthetic (-)-cytisine derivatives // Chem. Nat. Compd. 2013. Vol. 48. Pp. 1042-1046.

24. Zarubaev V.V., Golod E.L., Anfimov P.M., Shtro A.A., Saraev V.V., Gavrilov A.S., Logvinov A.V., Kiselev O.I. Synthesis and anti-viral activity of azolo-adamantanes against influenza A virus // Bioorg. Med. Chem. 2010. Vol. 18, N2. Pp. 839-848. 
Tsypysheva I.P. ${ }^{I^{*}}$, Galkin E.G. ${ }^{1}$, Koval'skaia A.V. ${ }^{1}$, Petrova P.R. ${ }^{2}$, Baikova I.P. ${ }^{l}$, Orshanskaia Ia.R. ${ }^{3}$, Fedorova V.A. ${ }^{3}$, Fedorov N.I. ${ }^{4}$, Galin F.Z. ${ }^{1,2}$, Zarubaev V.V. ${ }^{3}$ ANTIVIRAL ACTIVITY OF THE SUM OF ALKALOIDS OF GENISTA TINCTORIA AND ITS SEPARATE FRACTIONS ON THE INFLUENZA VIRUS A (H1N1) PDM09

${ }^{I}$ Ufa Chemistry Institute of the Russian Academy of Sciences, Oktiabria ave., 71, Ufa, Republic of Bashkortostan,

450054, (Russia), e-mail: tsipisheva@anrb.ru

${ }^{2}$ Bashkir State University, st. Zaki Validi, 32, Ufa, Republic of Bashkortostan, 450076 (Russia)

${ }^{3}$ Research Institute of Influenza, Professora Popova st., 15/17, St. Petersburg, 197376 (Russia)

${ }^{4}$ Ufa Institute of Biology of the Russian Academy of Sciences, Oktiabria ave., 69, Ufa, Republic of Bashkortostan, 450054 (Russia)

The ability of alkaloids of the aerial part of Genista tinctoria L. (a dye dye) collected during the flowering period in the Alsheevsky district of the Republic of Bashkortostan, to inhibit the reproduction of the influenza A (H1N1) virus pdm09 was studied. The component composition of the sum of alkaloids and individual fractions is determined by the chromatographymass spectrometric method. Cytotoxicity and anti-influenza properties of G. tinctoria alkaloids have been studied in vitro in the culture of MDCK cells with respect to the strain of influenza A / California / 07/09 (H1N1) pdm09, rimantadine was used as the reference preparation. Based on the data obtained, a 50\% cytotoxic dose of C50, a 50\% inhibitory dose of IC50, and a SI selectivity index characterizing the selectivity of the action of the sample against the virus were calculated. According to the data obtained, fraction 4 of the sum of alkaloids of G. tinctoria $(\mathrm{SI}=10)$, containing alkaloids 12-N-methylcytisine, $(-)$-cytisin, dlupanin, 12-N-formylcytisine, anagirine, baptilin, and fraction $5(\mathrm{SI}=7)$ containing $(-)$-cytisin, anagirine and baptiphlin. Anagyrin is a major component of fraction 4 , its content is $0.13 \%$ of the weight of air-dry raw materials, and baptilin-5, its content is $0.14 \%$. It should be noted that, in comparison with the sum of G. tinctoria alkaloids and fractions 2 and 3, fractions 4 and 5 enriched with tetracyclic quinolizidine alkaloids (anagirine and baptifolin) show more pronounced anti-influenza activity. The revealed regularity can serve as the basis for further optimization of the anti-influenza properties of these alkaloids by means of their chemical transformations.

Keywords: Genista tinctoria L., quinolizidine alkaloids, influenza A (H1N1) pdm09 virus, selectivity index.

\section{References}

1. Lahlou M. Pharmacol. Pharm., 2013, vol. 4, pp. 17-31.

2. Hanessian S. Natural Products in Medicinal Chemistry. John Wiley\&Sons. 2013. 480 p.

3. Martin K.W., Ernst E. Antivir. Ther., 2003, vol. 8, pp. 77-90.

4. $\quad$ Lin L.-T., Hsu W.-C., Lin C.-C. J. Tradit. Complement. Med., 2014, vol. 4, pp. 24-35.

5. Chattopadhyay D., Chawla-Sarkar M., Chatterjee T., Dey R.S., Bag P., Chakraborti S., Hassan Khan M.T. New Biothecnol., 2009, vol. 25, pp. 347-368.

6. Kurokawa M., Shimizu T., Watanabe W., Shiraki K. TOANTIMJ., 2010, vol. 2, pp. 49-57.

7. Sun F., Huang R. Curr. Drug Targets, 2014, vol. 15, pp. 175-183.

8. Tosun F., Kukukbayachy N., Adiguzel N., Ozkan S. Turk. J. Pharm. Sci., 2010, vol. 7, pp. 1-8.

9. Raheel R., Ashraf M., Ejaz S., Javeed A., Altaf I. Environ. Toxicol. Pharmacol., 2013, vol. 35, pp. $72-81$.

10. Ding P.-L., Huang H., Zhou P., Chen D.-F. Planta Med., 2006, vol. 72, pp. 854-856.

11. Ding P.-L., Liao Z.-X., Huang H., Zhou P., Chen D.-F. Bioorg. Med. Chem. Lett., 2006, vol. 16, pp. 1231-1235.

12. Atta-Ur-Rahman, Choudhary M. I., Parvez K., Ahmed A., Akhtar F., Nur-E-Alam M., Hassan N.M. J. Nat. Prod., 2000, vol. 63, pp. 190-192.

13. Woo E.R., Kim H.J., Kwak J.H., Lim Y.K., Park S.K., Kim H.S., Lee C.K., Park H. Arch. Pharm. Res., 1997, vol. 20, pp. 58-67.

14. Tsypysheva I.P., Galkin E.G., Baikova I.P., Fedorov N.I., Petrova P.R., Orshanskaya Ya.R., Fedorova V.A., Zarubaev V.V. Chem. Nat. Compd., 2015, vol. 51, pp. 1003-1005.

15. Tsypysheva I.P., Galkin E.G., Fedorov N.I., Orshanskaia Ia.R., Fedorova V.A., Zarubaev V.V. Khimiia rastitel'nogo syr'ia, 2016, no. 2, pp. 153-156. (in Russ.).

16. Dang Z., Jung K., Zhu L., Lai W., Xie H., Lee K.-H., Huang L., Chen C.-H. ACS Med. Chem. Lett., 2014, vol. 5, pp. 942-946.

17. Dang Z., Zhu L., Lai W., Bogerd H., Lee K.-H., Huang L., Chen C.-H. ACS Med. Chem. Lett., 2016, vol. 7, pp. $240-244$.

18. Minina S.A., Kaukhova I.E. Khimiia i tekhnologiia fitopreparatov. [Chemistry and technology of phytopreparations]. Moscow, 2009, 560 p. (in Russ.).

19. D'Arcy P., Mallard W.G., Reed J. Amdis Manual. Gaithersburg: National Institute of Standards and Technology. 2005.

20. Tsypysheva I.P., Galkin E.G., Erastov A.S., Karimova O.A., Baikova I.P., Rakhimov R.G., Koval'skaia A.V., Khalilova I.U., Abramova L.M., Iunusov M.S. Khimiia rastitel'nogo syr'ia, 2012, no. 4, pp. 181-186. (in Russ.).

21. Tsypysheva I.P., Galkin E.G., Erastov A.S., Karimova O.A., Baikova I.P., Koval'skaia A.V., Khalilova I.U., Abramova L.M., Iunusov M.S. Khimiia rastitel'nogo syr'ia, 2013, no. 4, pp. 55-60. (in Russ.).

22. Tsypysheva I.P., Petrova P.R., Baykova I.P., Galkin E.G., Fedorov N.I., Galin F.Z., Yunusov M.S. Nat. Prod. Ind. J., 2015, vol. 10, pp. 215-218.

23. Tsypysheva I.P., Koval'skaya A.V., Lobov A.N., Zarubaev V.V., Karpinskaya L.A., Petrenko I.A., Nikolaeva E.A., Shtro A.A., Yunusov M.S. Chem. Nat. Compd., 2013, vol. 48, pp. 1042-1046.

24. Zarubaev V.V., Golod E.L., Anfimov P.M., Shtro A.A., Saraev V.V., Gavrilov A.S., Logvinov A.V., Kiselev O.I. Bioorg. Med. Chem., 2010, vol. 18, N2, pp. 839-848.

\footnotetext{
* Corresponding author.
} 